\title{
Qualidade fisiológica de sementes de camomila [Chamomilla recutita (L.) Rauschert] após envelhecimento acelerado e estresse salino
}

\author{
ROLLWAGEN, D.G.; CARVALHO, R.I.N.* \\ Pontifícia Universidade Católica do Paraná, Campus São José dos Pinhais, Rodovia BR 376, km 14, CEP:83010- \\ 500, São José dos Pinhais-Brasil *ruy.carvalho@pucpr.br
}

\begin{abstract}
RESUMO: O objetivo do trabalho foi verificar a qualidade fisiológica de sementes da camomila submetidas a diferentes tempos de envelhecimento acelerado e ao estresse salino. Os experimentos foram realizados no Laboratório de Técnica de Sementes na PUCPR em São José dos Pinhais, Paraná. Os tempos de envelhecimento acelerado foram de 0,24, 48, 72 e 96 h e o estresse salino foi induzido por soluções de cloreto de sódio com potenciais osmóticos de $0 ;-0,2 ;-0,4 ;-0,6$; $-0,8 ;-1,0 \mathrm{MPa}$, ambos com quatro repetições. Foram avaliados a germinação, o índice de velocidade de germinação (IVG), o tempo médio de germinação (TMG), a velocidade media de germinação (VMG) e a entropia. O delineamento experimental adotado foi o de blocos casualizados. Concluiu-se que as sementes de camomila tiveram sua qualidade fisiológica afetada após $24 \mathrm{~h}$ de envelhecimento acelerado e sob estresse salino causado por solução de potencial osmótico de $-0,6 \mathrm{MPa}$.
\end{abstract}

Palavras-chave: germinação, envelhecimento acelerado, estresse salino, potencial osmótico

\begin{abstract}
Physiological quality of chamomile [Chamomilla recutita (L.) Rauschert] seeds after accelerated aging and salt stress. The aim of this study was to verify the physiological quality of chamomile seeds subjected to different accelerated aging periods and salt stress. The experiments were carried out in the Laboratory of Seed Technique, PUCPR, São José dos Pinhais, Paraná State, Brazil. The accelerated aging periods were 0, 24, 48, 72 and $96 \mathrm{~h}$ and the salt stress was induced by sodium chloride solutions with osmotic potentials of $0,-0.2,-0.4,-0.6,-0.8$, $-1.0 \mathrm{MPa}$, both with four replicates. The analyzed variables were: germination, germination velocity index (GVI), average germination time (AGT), average germination velocity (AGV) and entropy. Experimental design was in randomized blocks. Chamomile seeds had their physiological quality affected after $24 \mathrm{~h}$ of accelerated aging and under salt stress caused by the solution with osmotic potential of $-0.6 \mathrm{MPa}$.
\end{abstract}

Key words: germination, accelerated aging, salt stress, osmotic potential

\section{INTRODUÇÃO}

A camomila, Chamomilla recutita (L.) Rauschert, é uma planta aromática cujos capítulos florais são usados para fins terapêuticos. É nativa dos campos da Europa e amplamente cultivada em quase todo o mundo (Lorenzi \& Matos, 2002). Atualmente, é a planta medicinal com maior envolvimento de pequenos produtores rurais na região do sul do Brasil e com maior área de cultivo, como cultura de inverno propagada por sementes (Corrêa Junior et al., 2008). A germinação das sementes ultrapassa a $80 \%$ após 14 dias da semeadura, em temperaturas entre 10 e $20^{\circ} \mathrm{C}$ (Souza et al., 2007), mas a temperatura de $15^{\circ} \mathrm{C}$ é mais indicada para a boa germinação (Correa Junior et al., 1995).

A qualidade da semente é definida como 0 somatório de todos os atributos genéticos, físicos, fisiológicos e sanitários que afetam a sua capacidade de originar plantas da alta produtividade. A qualidade fisiológica da semente é a capacidade de desempenhar funções vitais, caracterizadas pela germinação, vigor e longevidade (Popinigis, 1985). Esta qualidade pode ser avaliada por diversas formas,

Recebido para publicação em 14/02/2009

Aceito para publicação em 22/03/2011

Rev. Bras. PI. Med., Botucatu, v.13, n.2, p.139-145, 2011. 
dentre as quais, o teste de envelhecimento acelerado que tem como princípio a manutenção das sementes a altas temperaturas $\left(40\right.$ a $\left.45^{\circ} \mathrm{C}\right)$ sob condições de umidade relativa de 90 a $100 \%$, por períodos variáveis de 24 a 72 horas para, em seguida, submetê-las às condições do teste padrão de germinação (PiñaRodrigues et al., 2004). Pela facilidade de aplicação vem sendo utilizado para análise de sementes de várias espécies como de melancia (Bhering et al., 2003), erva-doce (Torres, 2004), milho e soja (Dutra \& Vieira, 2004), tomate (Martins et al., 2006), beterraba (Silva \& Vieira, 2006) e trigo (Maia et al., 2007).

A germinação e o vigor das sementes também podem ser avaliados em condições de estresse salino provocado por soluções de $\mathrm{NaCl}, \mathrm{KCl}$ ou $\mathrm{CaCl}_{2}$ (Machado Neto et al., 2006). As maiores concentrações das soluções provocam efeitos mais acentuados em sementes com baixo vigor (Braccini et al., 1996; Moraes \& Menezes, 2003). Em campo, o excesso de sais solúveis, além de alterar o potencial hídrico do solo, age de forma tóxica para o embrião e influencia a germinação (Fonseca \& Perez, 1999). O efeito do estresse salino tem sido utilizado para avaliação fisiológica de sementes de outras espécies medicinais como de calêndula (Antonello et al., 2008). O efeito da redução do potencial osmótico por soluções de polietileno glicol, o que gera o estresse hídrico, sobre a germinação de sementes de anis, funcho e endro também foi estudado por Stefanello et al. (2008).

O objetivo deste trabalho foi verificar a qualidade fisiológica de sementes de camomila submetidas a diferentes tempos de envelhecimento acelerado e ao estresse salino.

\section{MATERIAL E MÉTODO}

Foram realizados dois experimentos independentes com sementes comerciais de camomila [Chamomilla recutita (L.) Rauschert] da família Asteraceae, no Laboratório de Técnica de Sementes da Pontifícia Universidade Católica do Paraná localizada em São José dos Pinhais no período de junho a julho de 2008.

As sementes foram beneficiadas em soprador (General Seed Blower), por 30 segundos, regulado na abertura 2,3 e, posteriormente, para caracterização das sementes utilizadas foi determinada a massa de mil sementes e a umidade inicial em estufa a $130^{\circ} \mathrm{C}$ por 1 hora (Brasil, 1992).

As amostras de $0,6 \mathrm{~g}$ de sementes sofreram o envelhecimento acelerado sob as condições de temperatura de $43^{\circ} \mathrm{C}$ por $24,48,72$ e 96 horas, além da testemunha. Após cada tempo na câmara, foi determinada a umidade de uma amostra com $0,25 \mathrm{~g}$ de sementes. Após o envelhecimento acelerado, as sementes foram submetidas ao teste de germinação em câmara BOD a $15^{\circ} \mathrm{C}$ e fotoperíodo de 16 horas para avaliação da manutenção do potencial germinativo. A assepsia das sementes após o tratamento na câmara de envelhecimento foi feita com hipoclorito de sódio a $1 \%$ por 3 minutos, seguida de lavagem com água deionizada. Foram avaliadas 100 sementes por caixa plástica com tampa (gerbox), desinfectada com álcool a 70\%, sobre papel germitest umedecido com $7 \mathrm{~mL}$ de água deionizada. Os papéis germitest foram umedecidos novamente no quarto dia com $3 \mathrm{~mL}$ de água deionizada.

Aplicou-se o estresse salino com soluções com potencias osmóticos de 0 (água pura); -0,2; -0,4; $-0,6 ;-0,8 ;$ e -1,0 MPa induzidos por soluções contendo $\mathrm{NaCl}$ calculados pela fórmula de Van't Hoff (Braga et al.,1999). A germinação das sementes sob estresse salino foi avaliada com 100 sementes por caixa plástica (gerbox), colocadas sobre papel germitest umedecido com $7 \mathrm{~mL}$ das respectivas soluções. A assepsia das caixas foi feita com álcool a $70 \%$. As caixas foram mantidas em câmara BOD a $15^{\circ} \mathrm{C}$ e fotoperiodo 16 horas. No quarto dia foram adicionados mais $3 \mathrm{~mL}$ de solução por caixa.

O delineamento experimental adotado foi 0 de blocos casualisados com cinco tratamentos e quatro repetições para o teste de envelhecimento acelerado e de seis tratamentos e quatro repetições para o teste de estresse salino.

Para os dois experimentos, as avaliações foram realizadas no quarto, sétimo, décimo primeiro e décimo quarto dia. As sementes eram consideradas germinadas quando ocorreu a protrusão da raiz primária.

Foram calculadas as seguintes variáveis:

-Germinação (\%)

-Índice de velocidade de germinação (IVG) dada pela equaçã

onde:

$$
\text { IVG }=\sum\left(n_{i} / t_{i}\right)
$$

$\mathrm{n}_{\mathrm{i}}=$ número de sementes que germinaram na data da avaliação,

$\mathrm{t}_{\mathrm{i}}=$ tempo da avaliação depois do início do teste; $i=4,7,10$ e 14 dias. Unidade: adimensional.

-Tempo médio de germinação (TMG) dada pela equação:

onde:

$$
\mathrm{TMG}=\left(\sum \mathrm{n}_{\mathrm{i}} \mathrm{t}_{\mathrm{i}}\right) / \sum \mathrm{n}_{\mathrm{i}},
$$

$\mathrm{n}_{\mathrm{i}}=$ número de sementes germinadas por

dia;

$\mathrm{t}_{\mathrm{i}}=$ tempo da avaliação depois do inicio do teste; $i=4,7,10$ e 14 dias. Unidade: dias.

-Velocidade média de germinação (VMG) dada pela formula:

onde:

$$
\mathrm{VMG}=1 / \mathrm{TMG}
$$

TMG = tempo médio de germinação, Unidade: dias ${ }^{-1}$. 
-Entropia calculada de acordo com procedimento adotado por Nassif \& Perez (2000). Unidade: Bits.

Os dados foram submetidos à análise de variância e as médias dos tratamentos foram submetidas à análise de regressão polinomial. A análise de correlação também foi realizada entre as variáveis.

\section{RESULTADO E DISCUSSÃO}

O beneficiamento com o soprador de sementes proporcionou a redução de $11,2 \%$ da massa total das sementes utilizadas, eliminando sementes menos densas e materiais inertes presentes. Segundo Souza et al. (2000), há quantidade excessiva de sementes chochas e de impurezas nos lotes, o que justifica seu beneficiamento antes da semeadura. A massa de mil sementes beneficiadas foi de 0,107 $\mathrm{g}$ e a umidade inicial de $6 \%$. Após o tratamento de envelhecimento acelerado ocorreu aumento da umidade para, em média, 35,9\% em função da permanência mais longa da semente no interior da câmara úmida, com coeficiente de correlação positivo de 0,81 .

As condições ambientais proporcionadas pelo envelhecimento acelerado interferiram na qualidade fisiológica das sementes logo no primeiro tratamento de 24 horas, reduzindo a germinação de $97 \%$ para $66 \%$ (Figura 1). Esta rápida redução do poder germinativo após 24 horas indica o baixo potencial de armazenamento das sementes estudadas. Por interpolação de dados, o tempo de 12 horas reduziria o percentual de germinação para $79 \%$. Tempos superiores a 48 horas reduziram a germinação abaixo de $50 \%$ e o tempo de 96 horas afetou a germinação de quase todas as sementes. A manutenção da capacidade germinativa após tempos mais longos de tratamento evidencia sementes mais vigorosas e com maior potencial de armazenamento. Torres (2004) constatou que o tempo de exposição de 72 horas na câmara de envelhecimento acelerado é indicado para avaliação do potencial fisiológico de sementes de erva-doce (Pimpinella anisum).

A elevada germinação de $97 \%$ obtida nas parcelas testemunhas indica a boa qualidade das sementes utilizadas, pois Souza et al. (2007) consideraram boa a germinação acima de $80 \%$, para sementes de camomila coletadas em campo e submetidas a diferentes temperaturas, e de $47 \%$, para sementes armazenadas por até dois anos. Pacheco et al. (2007) obtiveram germinação média de $53,12 \%$ para sementes comerciais de camomila.

O IVG das sementes de camomila foi influenciado mais intensamente pelo tempo de envelhecimento acelerado do que a germinação, pois o valor inicial de 23,8 foi reduzido à metade logo nas primeiras 24 horas de tratamento (Figura 1). Após 48 horas o IVG foi abaixo de 5,0 e chegou próximo a zero após 96 horas, quando a germinação já era inferior a $10 \%$.

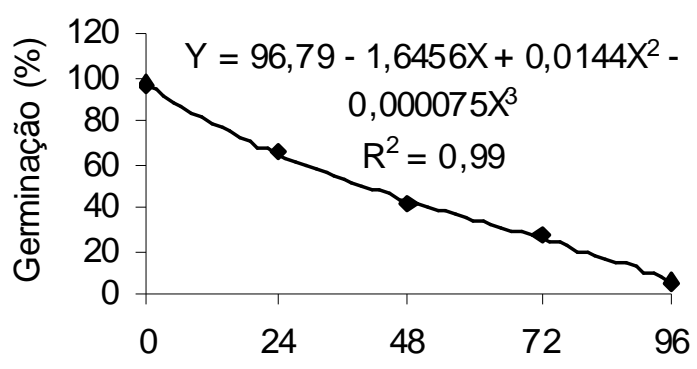

Tempo de envelhecimento ac elerado (horas)

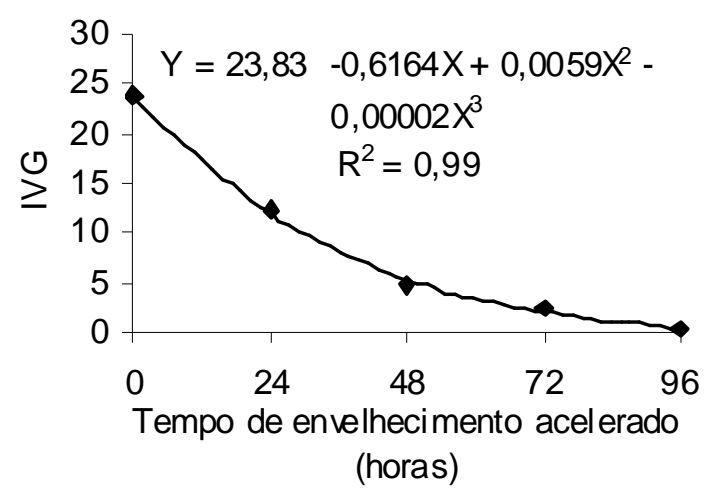

FIGURA 1. Germinação e índice de velocidade de germinação (IVG) de sementes de camomila após diferentes tempos de envelhecimento acelerado. São José dos Pinhais, PR. 2008.

O TMG aumentou de 3,8 a 11,8 dias em função do aumento do tempo de envelhecimento acelerado e, proporcionalmente, a VMG diminui neste período (Figura 2). Nas primeiras 24 horas, o TMG foi aumentado em cerca de $50 \%$, o que representou dois dias de atraso na germinação das sementes.

A entropia mede a organização de um sistema, de forma que quanto menor a entropia maiores são a organização e a sincronia do sistema (Nassif \& Perez, 2000). A entropia inicial foi baixa e atingiu o valor máximo após o tempo próximo às $48 \mathrm{~h}$ de envelhecimento acelerado (Figura 3). Em tempos mais longos de tratamento, a entropia decresceu, porém nestes tratamentos as outras variáveis analisadas como a germinação e o IVG já haviam sido muito afetados. A observação conjunta dos resultados obtidos indica que as sementes de camomila apresentaram alta sensibilidade ao estresse provocado por câmara de envelhecimento acelerado.

A correlação entre as variáveis germinação, IVG, TMG e VMG foi superior a 0,95, porém a

Rev. Bras. Pl. Med., Botucatu, v.13, n.2, p.139-145, 2011. 


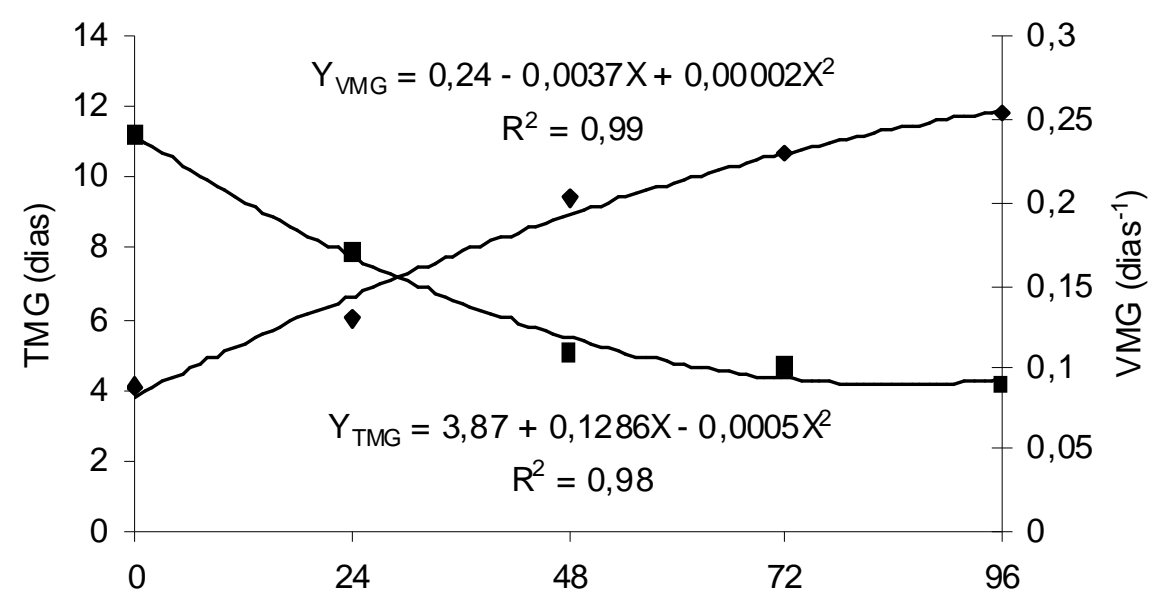

Tempo de envelhecimento acelerado (horas)

- TMG —VMG

FIGURA 2. Tempo médio de germinação (TMG) e velocidade média de germinação (VMG) de sementes de camomila após diferentes tempos de envelhecimento acelerado. São José dos Pinhais, PR. 2008.

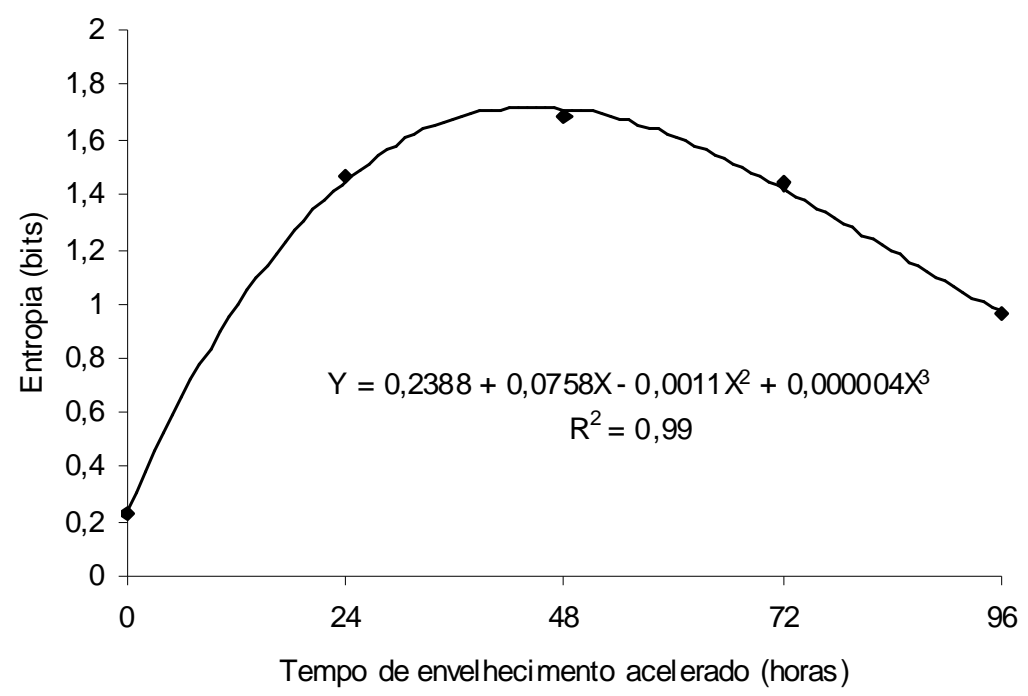

FIGURA 3. Entropia de sementes de camomila após diferentes tempos de envelhecimento acelerado. São José dos Pinhais, PR. 2008.

correlação da entropia com estas variáveis ficou entre 0,49 e 0,70 (Tabela 1). A menor correlação encontrada foi entre a entropia e a germinação $(-0,49)$, porém a correlação negativa evidencia que a maior germinação está relacionada à menor entropia, fato desejável para o manejo das sementes para testes em laboratório ou semeadura em campo.

A germinação no teste de estresse salino só foi inferior a $90 \%$ a partir do potencial osmótico de $-0,6 \mathrm{MPa}$, mas quando as sementes foram submetidas ao potencial -1,0 MPa, germinação foi rapidamente reduzida para níveis inferiores a $25 \%$ (Figura 4). $O$ potencial osmótico que limita a germinação das sementes varia de acordo com a espécie e cultivar. Potenciais osmóticos de -0,1 e -0,2, causados por soluções de polietileno glicol, foram suficientes para reduzir drasticamente a germinação de sementes de funcho (Foeniculum vulgare Miller) e endro (Anethum graveolens L.), respectivamente (Stefanello et al., 2008). Mesmo sementes de maior massa, como as de feijão da cultivar IAPAR 44, tiveram reduzida germinação em potenciais osmóticos a partir de -0,2 MPa (Moraes et al., 2005), porém em sementes da cultivar IAC-Carioca-80SH não houve interferência na germinação por potenciais até -0,6 MPa (Machado Neto et al., 2006). 
TABELA 1. Correlação entre germinação, índice de velocidade de germinação (IVG), tempo médio de germinação (TMG), velocidade média de germinação (VMG) e entropia, no teste de envelhecimento acelerado. São José dos Pinhais, PR. 2008.

\begin{tabular}{lccccc}
\hline Variáveis & Germinação & IVG & TMG & VMG & Entropia \\
\hline Germinação & 1,00 & & & & \\
IVG & 0,97 & 1,00 & & & \\
TMG & $-0,96$ & $-0,95$ & 1,00 & & \\
VMG & 0,95 & 0,99 & $-0,96$ & 1,00 & \\
Entropia & $-0,49$ & $-0,67$ & 0,50 & $-0,70$ & 1,00 \\
\hline
\end{tabular}
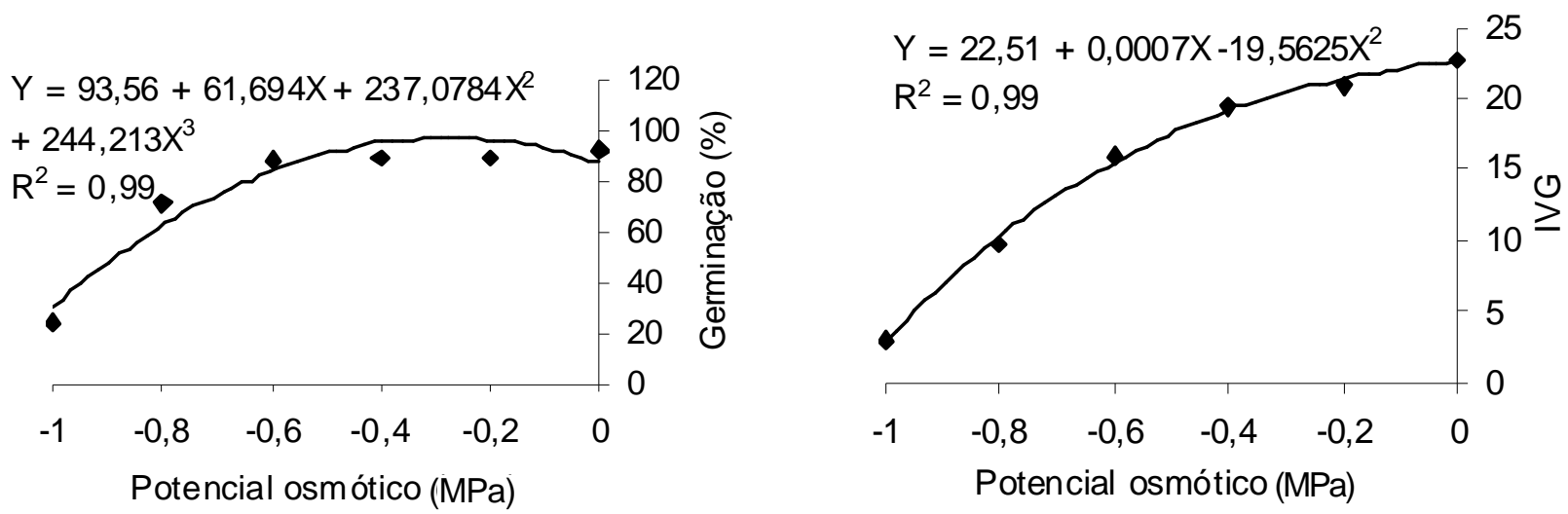

FIGURA 4. Germinação e índice de velocidade de germinação (IVG) de sementes de camomila submetidas a diferentes potenciais osmóticos. São José dos Pinhais, PR. 2008.

A interferência da salinidade sobre o IVG foi mais drástica do que sobre a germinação, pois com o potencial de -0,2 MPa houve pequena redução que se acentuou de forma quadrática até o potencial de -1,0 MPa (Figura 4). Embora, a germinação não tenha sido afetada nos potenciais mais baixos, o menor IVG restringe a facilidade do manejo das sementes em laboratório ou em campo. O TMG das sementes de camomila aumentou de quatro para cerca de nove dias até o potencial osmótico de -1,0 MPa e, de forma inversamente proporcional, a VMG foi reduzida (Figura 5).

A entropia inicial do sistema foi baixa, fato associado à boa qualidade das sementes utilizadas que apresentaram elevada germinação em um tempo curto. A elevação do potencial osmótico até -0,6 MPa, embora tenha afetado pouco a germinação, provocou, além da redução do IVG, aumento da entropia, identificando a desordem da população de sementes ao longo do teste de germinação. A alteração do potencial osmótico até $-1,0 \mathrm{MPa}$ promoveu nova queda de entropia, porém associada à queda de germinação e IVG e aumento do TMG, tornando inviável esta condição para o bom uso das sementes (Figura 6).

Concluiu-se que o envelhecimento acelerado sob temperatura de $43^{\circ} \mathrm{C}$ afeta negativamente a qualidade fisiológica de sementes de camomila, a partir de 24 horas de estresse, reduzindo a germinação e o índice de velocidade de germinação e aumentando o tempo médio para germinação. A qualidade das sementes também é afetada pelo estresse salino causado por solução de $\mathrm{NaCl}$ com potencial osmótico inferior a -0,6 MPa.

A correlação entre a germinação e as demais variáveis foi diretamente proporcional ao IVG e VMG e inversamente proporcional ao TMG e à entropia (Tabela 2). As correlações encontradas entre a entropia e as demais variáveis foram as mais baixas, indicando que outros fatores estão envolvidos nas modificações de seus valores, porém foram semelhantes às obtidas no teste de envelhecimento acelerado, confirmando este comportamento para as sementes de camomila estudadas.

Concluiu-se que o envelhecimento acelerado sob temperatura de $43^{\circ} \mathrm{C}$ afeta negativamente a qualidade fisiológica de sementes de camomila, a partir de 24 horas de estresse, reduzindo a germinação e o índice de velocidade de germinação e aumentando o tempo médio para germinação. A qualidade das sementes também é afetada pelo estresse salino causado por solução de $\mathrm{NaCl}$ com potencial osmótico inferior a -0,6 MPa. 


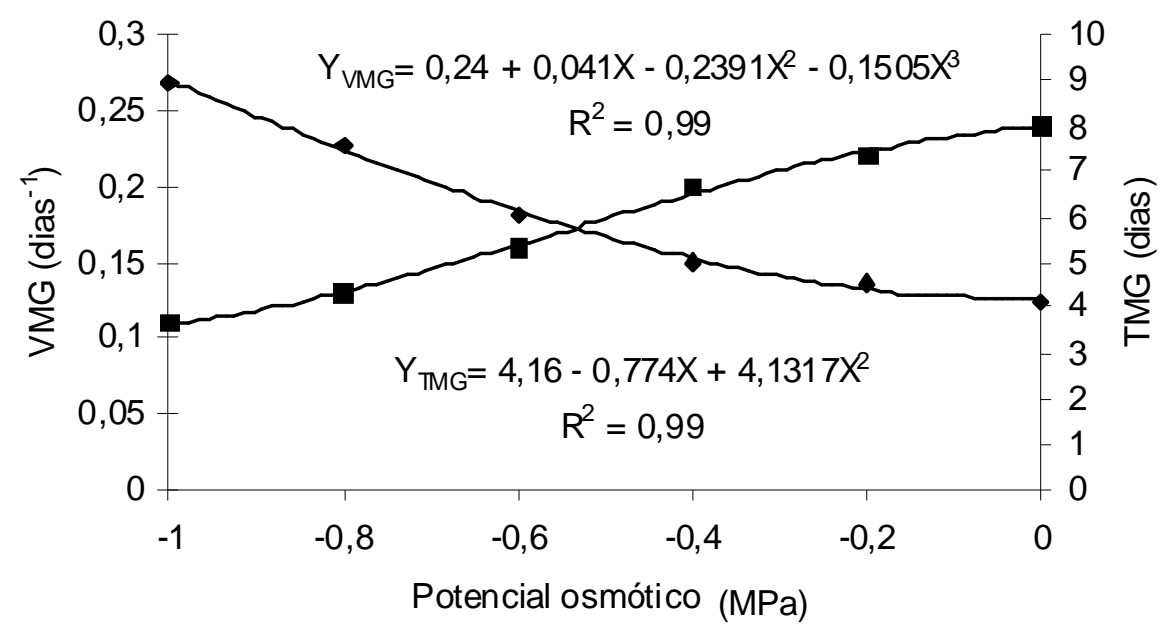

- TMG 匹VMG

FIGURA5. Velocidade média de germinação (VMG) e tempo médio de germinação (TMG) de sementes de camomila submetidas a diferentes potenciais osmóticos. São José dos Pinhais, PR. 2008.

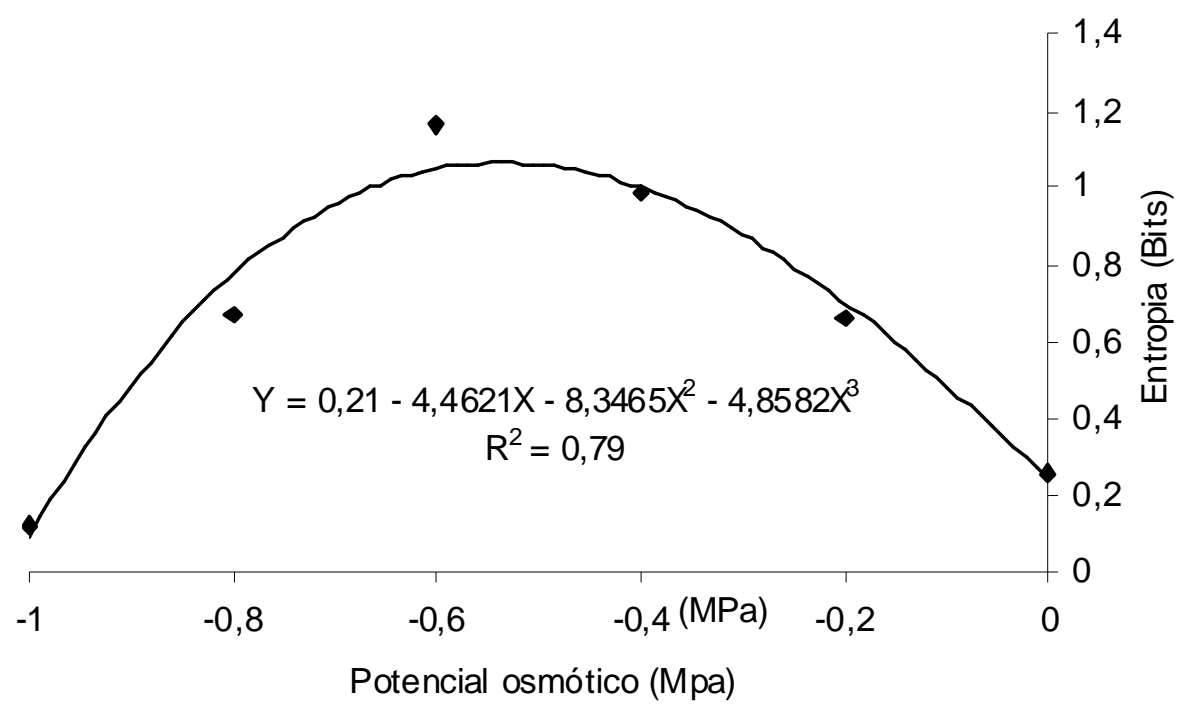

FIGURA 6. Entropia de sementes de camomila submetidas a diferentes potenciais osmóticos. São José dos Pinhais, PR. 2008.

TABELA2. Correlação entre as variáveis germinação, índice de velocidade de germinação (IVG), tempo médio de germinação (TMG), velocidade média de germinação (VMG) e entropia, no teste de estresse salino. São José dos Pinhais, PR. 2008.

\begin{tabular}{lccccc}
\hline Variáveis & Germinação & IVG & TMG & VMG & Entropia \\
\hline Germinação & 1,00 & & & & \\
IVG & 0,92 & 1,00 & & & \\
TMG & $-0,88$ & $-0,99$ & 1,00 & & \\
VMG & 0,79 & 0,96 & $-0,98$ & 1,00 & \\
Entropia & $-0,49$ & $-0,57$ & 0,60 & $-0,66$ & 1,00 \\
\hline
\end{tabular}




\section{REFERÊNCIA}

ANTONELLO, L.M. et al. Efeito do estresse salino na germinação de sementes de calêndula (Calendula officinalis L.). Revista Brasileira de Plantas Medicinais, v.10, n.4, p.117-20, 2008.

BHERING, M.C. et al. Avaliação do vigor de sementes de melancia (Citrullus lunatus Schrad.) pelo teste de envelhecimento acelerado. Revista Brasileira de Sementes, v.25, n.2, p.1-6, 2003.

BRACCINI, A.L. et al. Germinação e vigor de sementes de soja sob estresse hídrico induzido por soluções de cloreto de sódio, manitol e polietileno glicol. Revista Brasileira de Sementes, v.18, n.1, p.10-6, 1996.

BRAGA, L.F. et al. Efeito da disponibilidade hídrica do substrato na qualidade fisiológica de sementes de feijão. Revista Brasileira de Sementes, v.21, n.2, p.95102, 1999.

BRASIL. Ministério da Agricultura e Reforma Agrária. Regras para análise de sementes. Brasília-DF: Departamento Nacional de Produção Vegetal - SNA/ DNPV/CLAV, 1992. 365p.

CORREA JUNIOR, C. et al. Efeito da luz e da temperatura da germinação de sementes de camomila (Matricaria recutita). Revista Brasileira de Sementes, v.17, n.2, p.137-40, 1995.

CORREA JUNIOR, C. et al. O cultivo da camomila [Chamomilla recutita(L.) Rauschert]. Curitiba: EMATER, 2008. 44p.

DUTRA, A.S.; VIEIRA, R.D. Envelhecimento acelerado como teste de vigor para sementes de milho e soja. Ciência Rural, v.34, n.3, p.715-21, 2004.

FONSECA, S.C.L.; PEREZ, S.C.J.G.A. Efeito de sais e da temperatura na germinação de sementes de olho-dedragão (Anadenanthera pavonina L. - FABACEAE). Revista Brasileira de Sementes, v.21, n.2, p.70-7, 1999. LORENZI, H.; MATOS, F.J.A. Plantas medicinais no Brasil: nativas e exóticas. Nova Odessa: Instituto Plantarum, 2002. 512p.

MACHADO NETO, N.B. et al. Deficiência hídrica induzida por diferentes agentes osmóticos na germinação e vigor de sementes de feijão. Revista Brasileira de Sementes, v.28, n.1, p.142-8, 2006.

MAIA, A.R. et al. Efeito do envelhecimento acelerado na avaliação da qualidade fisiológica de sementes de trigo.
Ciência e Agrotecnologia, v.31, n.3, p.678-84, 2007. MARTINS, C.C. et al. Metodologia para a avaliação de sementes de tomate. Horticultura Brasileira, v.24, n.3, p.301-4, 2006.

MORAES, G.A.F.; MENEZES, N.L. Desempenho de sementes de soja sob condições diferentes de potencial osmótico. Ciência Rural, v.33, n.2, p.219-26, 2003.

MORAES, G.A.F.; MENEZES, N.L.; PASQUALLI, L.L. Comportamento de sementes de feijão sob diferentes potenciais osmóticos. Ciência Rural, v.35, n.4, p.77680, 2005.

NASSIF, S.M.L.; PEREZ, S.C.J.G. Efeito da temperatura na germinação de sementes de amendoim-do-campo (Pterogyne nitens Tul.). Revista Brasileira de Sementes, v.22, n.1, p.1-6, 2000.

PACHECO A.C. et al. Germinação de sementes de camomila [Chamomilla recutita (L.) Rauschert] e calêndula (Calendula officinalis L.) tratadas com ácido salicílico. Revista Brasileira de Plantas Medicinais, v.9, n.1, p.61-7, 2007.

PIÑA-RODRIGUES, F.C.M.; FIGLIOLIA, M.B.; PEIXOTO, M.C. Teste de qualidade. In: FERREIRA, A.G.; BORGHETTI, F. (Orgs.). Germinação: do básico ao aplicado. Porto Alegre: Artmed, 2004. p.283-97.

POPINIGIS, F. Fisiologia da semente. Brasília: s.ed., 1985. 289p.

SILVA, J.B.; VIEIRA, R.D. Avaliação do potencial fisiológico de sementes de beterraba. Revista Brasileira de Sementes, v.28, n.2, p.128-34, 2006.

SOUZA, J.R.P.; AGUILERA, D.B.; TAKAHASHI, L.S.A. Método para beneficiamento de sementes de camomila (Matricaria chamomilla L.). Revista Brasileira de Sementes, v.22, n.1, p.38-41, 2000.

SOUZA, J.R.P. et al. Tempo de armazenamento e temperatura na porcentagem e velocidade de germinação das sementes de camomila. Ciência Rural, v.37, n.4, p.982-6, 2007.

STEFANELLO, R. et al. Efeito do estresse hídrico na germinação e no vigor de sementes de anis (Pimpinella anisum L.), funcho (Foeniculum vulgare Miller) e endro (Anethum graveolens L.). Revista Brasileira de Plantas Medicinais, v.10, n.2, p.68-74, 2008.

TORRES, S.B. Teste de envelhecimento acelerado em sementes de erva-doce. Revista Brasileira de Sementes, v.26, n.2, p.20-4, 2004. 